\title{
Effect of probiotic strains mixture administration on serum interleukins concentration, lymphocyte proliferation and DNA damage in rams
}

\author{
H.M.A. Abdelrazek ${ }^{1}$, M.S. Yusuf ${ }^{2}$, S.A. Ismail ${ }^{4}$ and R.A. Elgawish ${ }^{3,5}$ \\ Suez Canal University, Faculty of Veterinary Medicine, ${ }^{1}$ Department of Physiology, ${ }^{2}$ Department of Nutrition and Clinical Nutrition, \\ ${ }^{3}$ Department of Forensic Medicine and Toxicology, Ismailia 41522, Egypt \\ ${ }^{4}$ Zagazig University, Faculty of Veterinary Medicine, Department of Clinical Pathology, Zagazig 44111, Egypt
}

KEY WORDS: rams, probiotics, leukocytes, cytokines, lymphocyte transformation
Received: 15 January 2015

Revised: 31 October 2015

Accepted: 25 November 2015

${ }^{5}$ Corresponding author:

e-mail: reemshab@gmail.com

\begin{abstract}
Probiotics are live bacteria that could exert health beneficial effects; however, their immunological effects in sheep are still scarce. The aim of this study was to investigate the immunomodulatory role of probiotics in 12 rams weighing $30-35 \mathrm{~kg}$. The animals were divided into 2 groups ( 6 animals each), one group served as a control and the other as a probiotic treated one. Treated rams were given orally commercial probiotic strains (Sacharomyces cerevisiae, Lactobacillus acidophilus, Lactobacillus plantarum and Enterococcus faecalis) mixture in a dose of $10 \mathrm{~g} / \mathrm{head} / \mathrm{day}$ for one month. Blood samples were collected from control and treated rams at the end of the whole experimental period. Total and differential leukocyte counts (TLC and DLC), interleukin 10 (IL-10) and 12 (IL-12) serum concentration, IL-10/IL-12 ratio, lymphocyte transformation and DNA damage (comet assay) were determined. TLC in the blood of treated rams decreased significantly $(P=0.009)$, the serum levels of $\mathrm{IL}-10$ and $\mathrm{IL}-12$ were not significantly changed, while IL-10//L-12 ratio was significantly $(P=0.03)$ increased after probiotic mixture administration in rams. The administration of probiotic mixture significantly $(P=0.0001)$ enhanced the transformation of lymphocytes in rams' blood. After probiotic mixture administration, the percent of DNA in the comet tail declined significantly $(P=0.02)$ from $2.75 \%$ to $2.57 \%$. The present study demonstrated that leukocytes, cytokine production, lymphocyte transformation and DNA integrity were differentially influenced by the tested probiotic strains mixture. The biological importance of specific effects of probiotics in sheep remains to be determined.
\end{abstract}

\section{Introduction}

Bacteria, fungi or yeasts that have favourable effects on hosts are called probiotics, which can be classified into colonizing species (Lactobacillus spp., Enterococcus spp. and Streptococcus spp.) and free, non-colonizing species (Bacillus and Saccharomyces cerevisiae).
It has been shown that probiotics influence both innate and adaptive immunity through direct contact with epithelial and immune cells, or by their ability to modify the composition and activity of the gut microbiota. They exert their protective effects by multiple immune and non-immune mechanisms (Lebeer et al., 2008), i.e. by increasing phagocytosis (de Moreno de LeBlanc et al., 2010), modifying 
cytokines production by different cell populations (Vizoso Pinto et al., 2009) or enhancing immunoglobulin A (IgA) production (Galdeano and Perdigón, 2006). One of the principal mechanisms of probiotics protection against gastroenteric infections is via modulation of pro- and anti-inflammatory cytokines synthesis, but the pathways and cells involved in this mechanism have not been identified yet (Mileti et al., 2009). In fact, not all microorganisms have the same effect on the host, so that probiotic properties are strain and host-specific. In this regard, it is not possible to extrapolate the effects found with one probiotic strain from another.

Little research has been conducted to evaluate the effect of probiotics on the immune system of ruminants. Results obtained on Jersey dairy cow showed that Bovamine (a probiotic formulation that contains Lactobacillus acidophilus strain NP51a lactic acid producer, and Probionibacterium freudenreichii - a lactic acid utilizer) administration seemed to be accompanied with the modification of the immune response. Supplementing Bovamine to dairy cattle significantly increased expression of $\mathrm{CD} 25^{+} \mathrm{T}$ cells and $\mathrm{CD}^{+} \mathrm{T}$ cells in polymorphonuclear (PMN) cells under concanavalin A stimulation (Osman, 2012). Additionally, stimulation of PMN cells with probiotic mixture in vitro increased expression of $\mathrm{CD}^{+}, \mathrm{CD} 25^{+}$and $\mathrm{CD} 9^{+}$cells (Hua et al., 2010). Moreover, Bovamine triggered expansion of $\mathrm{CD} 335^{+}$ natural killer (NK) cells in peripheral blood of dairy cattle.

As it is stated in other available data, the effect of probiotics on animals' immunity is controversial. Some probiotics stimulated the immune system (de Moreno de LeBlanc et al., 2010) and other had anti-allergic or anti-inflammatory effects (Mileti et al., 2009). However, till now, no reports of the effects of probiotics on the immune system in rams have been documented. So the objective of the present work was established to broaden the knowledge about the probiotics influence on the immune modulation in sheep by assessing the impact of probiotic mixture on the leukocytes count profiles, interleukins 10 (IL-10) and 12 (IL-12) serum concentration, lymphocyte transformation and DNA integrity.

\section{Material and methods}

\section{Animals and treatment}

The study was carried out on 12 Baladi rams weighting $30-35 \mathrm{~kg}$ in a private farm in Ismailia province (Egypt). The animals were examined and found free from internal and external parasites. The health condition of the rams was carefully checked by veterinarian throughout the whole experimental period. The rams did not show any signs of disease or inflammatory condition during the experimental period. The treated rams $(n=6)$ were given a commercial probiotic mixture of Sacharomyces cerevisiae, Lactobacillus acidophilus, Lactobacillus plantarum and Enterococcus faecalis at $10^{5}, 10^{6}, 10^{4}$ and $10^{5}$ colony-forming unit (CFU) $\cdot \mathrm{g}^{-1}$, respectively (BIM-4000, Grotec USA, Inc. Carpinteria, CA, USA) in a dose of $10 \mathrm{~g} / \mathrm{head} /$ day dissolved in $100 \mathrm{ml}$ of water that was given at once. Treatment continued for one month. All animals were allowed free access to water and feed (\%: Egyptian clover 25, wheat straw 35, yellow maize 15 , wheat bran 15 , broken horse beans 9 , common salt 0.5 , vitamins and minerals premix 0.5 ). This diet was formulated to fulfil nutritional requirements of growing sheep. The animals were kept under the same environmental conditions.

\section{Blood samples}

Three blood samples were collected from each control and treated ram after the end of experimental period. The first sample was collected into EDTA containing tubes for leukocyte count. The second sample was collected into a plain tube for serum separation and interleukins concentration assay. The third sample was collected into lithium heparinized tubes for lymphocyte transformation test (LTT) and comet assay.

\section{Total and differential leukocyte count}

Blood samples collected into EDTA containing tubes were immediately put on ice. Total leukocyte count (TLC) and the percentage for each type of white cells were calculated according to Feldman et al. (2000).

\section{Interleukin assay}

Blood samples were collected into plain tubes. After that sera were separated by centrifugation at $3000 \mathrm{rpm}$ for $15 \mathrm{~min}$. The obtained sera were stored at $-20^{\circ} \mathrm{C}$. Serum IL-10 and IL-12 concentration were measured according to manufacturers' instructions using commercial ELISA kits for IL-10 (Cat. No. 106454-2, Genorise Scientific Inc. Glen Mills, PA, USA) and IL-12 (Cat. No. E-EL-S0036, Elabscience Biotechnology Co., Wuhan, China), respectively.

\section{Lymphocyte transformation test}

Blood samples collected into lithium heparinized tubes were immediately put in bags with ice and transferred to the laboratory for LTT. The separated 
buffy coat was washed with RPMI-1640 medium (Cat. No. R8758, Sigma-Aldrich; St. Louis, MO, USA) and the sediment of washed lymphocytes was re-suspended in $1 \mathrm{ml}$ of RPMI-1640 medium containing $10 \%$ of foetal calf serum (Cat. No. F2442, Sigma-Aldrich; St. Louis, MO, USA). LTT was carried out by using methyl thiazolyl tetrazolium (MTT) reduction procedure toghether with a colorimetric method based on absorbance data (optical density) measured at $490 \mathrm{~nm}$ (Gao et al., 2008).

\section{Single cell gel electrophoresis (comet assay)}

The comet assay was used to study and to compare with the effect of the probiotic mixture on DNA damage. The procedure began by incubating lymphocytes for $2 \mathrm{~h}$. Negative controls were set up by incubating lymphocytes with the solvent dimethyl sulphoxide (DMSO) at a final concentration of $1 \%$. Ten microlitres of treated lymphocytes were mixed with $120 \mu \mathrm{l}$ of $0.5 \%$ low-melting agarose and layered on the surface of glass slides previously coated with $140 \mu \mathrm{l}$ of $1 \%$ normal-melting agarose. After the application of cover slips, the slides were allowed to gel at $4{ }^{\circ} \mathrm{C}$ for $20 \mathrm{~min}$. After a careful removal of the cover slips, a second layer of $0.5 \%$ low-melting agarose was pipetted onto the slides and allowed to form gel for a further $20 \mathrm{~min}$ also at $4^{\circ} \mathrm{C}$. Slides without cover slips were immersed in a cold lysing solution overnight at $4{ }^{\circ} \mathrm{C}$. Before electrophoresis, the slides were equilibrated in alkaline electrophoresis solution $(1 \mathrm{mM}$ disodium salt of ethylene diamine tetra acetic acid and $300 \mathrm{mM}$ sodium hydroxide, $\mathrm{pH}>13$ ) for $20 \mathrm{~min}$. Electrophoresis was carried out in the same buffer for $25 \mathrm{~min}$ at $25 \mathrm{~V}$ and $300 \mathrm{~mA}$. Then slides were washed gently $2-3$ times, 5 min each with $0.4 \mathrm{M}$ Tris buffer at $\mathrm{pH} 7.5$ (neutral buffer). After final wash, the neutral buffer was drained, and slides were washed with water. Air-dried slides were then stained using silver nitrate solution $\left(0.2 \mathrm{mg} \cdot \mathrm{ml}^{-1}\right)$ after appropriate fixation (Kizilian et al., 1999). The whole procedure was carried out in a dim light to minimize artefacts of DNA damage. Analysis was performed at a $100 \times$ magnification by using a light microscope (Nikon, China) after coding the slides. At least 100 cells were screened per slide.

\section{Statistical analysis}

The data was expressed as mean \pm standard error (SE). The results obtained for control and treated rams were compared by t-test using GraphPad Prism (GraphPad Software; San Diego, CA, USA). A $P$-value below 0.05 was considered statistically significant.

\section{Results}

\section{Total and differential leukocyte count}

Baladi rams administered probiotic strains mixture exhibited significant $(P=0.009)$ decrease in TLC as well as significant $(P=0.02)$ increase in neutrophils percent compared to control group. Lymphocytes, monocytes and acidophils numerically declined after probiotic treatment but didn't reach a significant level (Table 1).

\section{Interleukins ratio and lymphocytes transformation assay}

In comparison to control rams, tested probiotic strains mixture did not affect IL-10 and IL-12 serum concentration in the tested group. However, there was a significant $(P=0.03)$ increase in the IL-10/IL-12 ratio after probiotic strains mixture administration. The administration of probiotic mixture enhanced significantly $(P=0.0001)$ the transformation of lymphocytes compared to control group (Table 2).

Table 1. Total leukocytes count (TLC) per $\mu$ l of plasma and differential leukocytes counts (\%) in control and probiotic mixture administrated in Baladi rams (mean $\pm S E$ )

\begin{tabular}{lll}
\hline Indices & Group & \\
\cline { 2 - 3 } & control & probiotic treatment
\end{tabular}

TLC per $\mu$ l of plasma $10725 \pm 548.8^{\mathrm{a}} 8091 \pm 546.8^{\mathrm{b}} \quad 0.009^{* *}$ Lymphocytes, \% $\quad 55.1 \pm 1.5 \quad 45.6 \pm 4.5 \quad 0.06$ Neutrophils, \% $\quad 37.6 \pm 1.5^{\mathrm{a}} \quad 49.8 \pm 3.9^{\mathrm{b}} \quad 0.02^{*}$ Monocytes, $\% \quad 3.3 \pm 0.4 \quad 2.9 \pm 0.4 \quad 0.5$

Acidophils, \% $\quad 3.4 \pm 0.6 \quad 1.8 \pm 0.5 \quad 0.07$

$a, b$ different superscripts within the same row indicate significant differences at $P<0.05 ;{ }^{*} P<0.05,{ }^{*} P<0.01$

Table 2. Effect of probiotic strains mixture administration on serum interleukin IL-10 and IL-12 concentrations $\left(\mathrm{pg} \cdot \mathrm{ml}^{-1}\right)$, IL-10/L-12 ratio and lymphocytes proliferation in Baladi rams (mean $\pm \mathrm{SE}$ )

\begin{tabular}{|c|c|c|c|}
\hline \multirow{2}{*}{ Indices } & \multicolumn{2}{|l|}{ Group } & \multirow{2}{*}{$P$} \\
\hline & control & probiotic treatment & \\
\hline $\mathrm{IL}-10, \mathrm{pg} \cdot \mathrm{ml}^{-1}$ & $67.3 \pm 6.6$ & $81.6 \pm 5.3$ & 0.1 \\
\hline $\mathrm{IL}-12, \mathrm{pg} \cdot \mathrm{ml}^{-1}$ & $120.8 \pm 9.5$ & $145.2 \pm 3.9$ & 0.08 \\
\hline IL-10/IL-12 ratio & $0.556 \pm 0.012^{\mathrm{a}}$ & $0.613 \pm 0.012^{b}$ & $0.03^{*}$ \\
\hline $\begin{array}{l}\text { Lymphocyte } \\
\text { transformation }{ }^{1}\end{array}$ & $0.8 \pm 0.03^{a}$ & $1.7 \pm 0.07^{b}$ & $0.0001^{* * *}$ \\
\hline
\end{tabular}

${ }^{1}$ lymphocyte transformation measured by using MTT colorimetric assay, optical density measured at $490 \mathrm{~nm}$; a,b different superscripts within the same row indicating significant differences at $P<0.05$; ${ }^{*} P<0.05,{ }^{* * *} P<0.001$

\section{Comet assay}

After probiotic strains mixture administration, the percent of DNA in the comet tail declined significantly $(P=0.02)$ from 2.75 to $2.57 \%$ (a $6.5 \%$ decrease) as shown in Figure 1. 


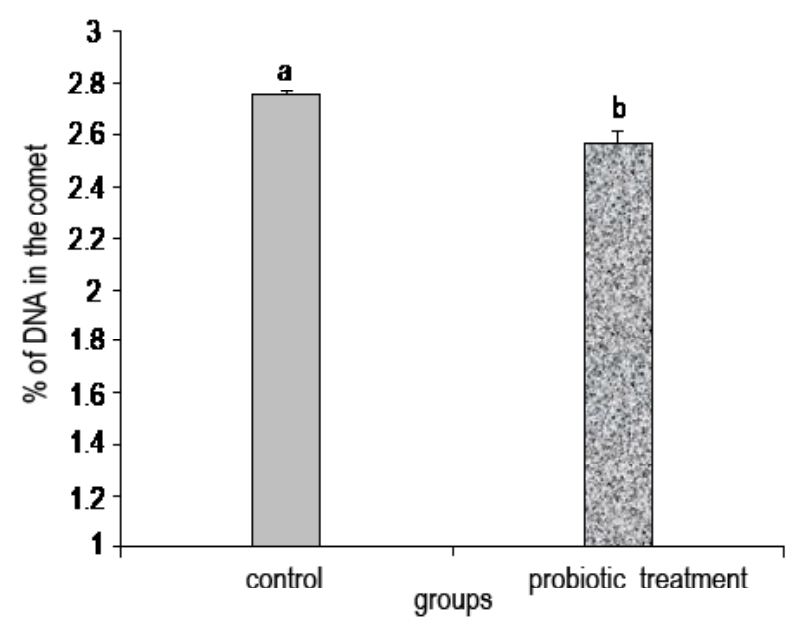

Figure 1. Effect of probiotic administration on DNA damage in lymphocyte of Baladi rams. Level of DNA strand breaks (mean \pm SE) is expressed as percentage of DNA in comet tail. $a, b$ bars with different superscript differ significantly at $P<0.05$

\section{Discussion}

Immunomodulation through stimulation or suppression may help in maintaining a disease-free state. Immunomodulatory agents obtained from plant and of animal origin enhance immune responsiveness of an organism against a pathogen by activating the immune system. Probiotic consumption is reported to exert a myriad benefits such as enhanced immune response, balancing of colonic microbiota, vaccine adjuvant effects, reduction of faecal enzymes implicated in cancer initiation and treatment of travel- and antibiotic-related diarrhoea (Nicole and Dan, 2010).

In the present study, the administration of probiotic strains mixture caused a significant $(P=0.009)$ decrease in total leukocytes count that might suggest the anti-inflammatory role of this probiotic strains mixture. However, neutrophils percentage was significantly $(P=0.02)$ increased, suggesting that probiotic supplementation could modulate non-specific immune response. Neutrophils are the first line of defense capable of responsing in a wide range, via chemotaxis, phagocytosis, exocytosis, intracellular and extracellular killing of microorganisms (Ishikawa and Miyazaki, 2005). The obtained results are in agreement with those stated by Babar et al. (2012) who reported a significant increase in neutrophils in Wistar rats after probiotic treatment. In contrary, Kunavue and Lien (2012) found non-significant effect of probiotic treatment on the number of blood cells in pigs. In this study, there is observed nonsignificant change in lymphocytes, monocytes, acidophils and basophils percentages between control and probiotic treated rams. These results are coincided with the results of Ismail (2013) who reported significant increase in neutrophils with non-significant change in acidophils and basophils percentages in probiotic treated diabetic patients in comparison to control diabetic ones. Moreover, the obtained results are in partial agreement with those of Guillen (2009) who found increased level of granulocytes (including neutrophil) and monocytes in peripheral blood in cattle fed Bovamine. The variation in probiotic results concerning DLC may be attributed to the difference in probiotic strain, combination of probiotic strains, dose, duration and host factors (Kuitunen, 2013).

The result of the present study demonstrates that there was no significant difference in the antiinflammatory IL-10 and pro-inflammatory IL-12 serum concentration between control and probiotic mixture treated rams. Moreover, the IL-10/IL-12 ratio was significantly $(P=0.03)$ improved after probiotic treatment. There were considerable differences between different probiotic species in their ability to induce IL-10 (Medina et al., 2007). IL-12 was proven as a key cytokine in activation of T-helper 1 (Th1) immune response by stimulating $\mathrm{T}$ cells and NK cells to secrete interferon (IFN)- $\gamma$ which is essential for successful defence against intracellular pathogen infections, whereas IL-10 results in a negative regulation of this process and induces antibody-mediated immune response (Lopez et al., 2010). Moreover, IL-10 is a macrophage-derived cytokine that down-regulates IFN- $\gamma$ production, thus opposing the action of IL-12 on T cells and NK cells (D'Andrea et al., 1993). The IL-10/IL-12 ratio was frequently used in the assessment of immune status as a measure of the balance between antiinflammatory and pro-inflammatory state (Hamer et al., 2010), or Th1 vs Th2 dominance (Bien et al., 2009). The increased IL-10/IL-12 ratio, which was observed in this study, confirmed the potential antiinflammatory effect of probiotic and its possible role in modulating inflammatory conditions. Also it is generally accepted that certain Lactobacillus strains are able to induce pro-inflammatory cytokines, such as IL-12, as well as anti-inflammatory cytokines, such as IL-10 (Hessle et al., 2000). It is worth to note that $\mathrm{T}$ cell is not the only cell type which responds to probiotic stimulants producing cytokines. Antigen-presenting cells, including dendritic cells, monocytes and B cells, in peripheral blood mononuclear cell (PBMC) also contribute to significant proand anti-inflammatory cytokines induction by probiotics within a short time after stimulation (Dong et al., 2012). Moreover, probiotic can enhance IgA secretion in dairy cattle (Guillen, 2009). 
In the present study, the probiotic strains mixture significantly $(P=0.0001)$ increased the lymphocyte transformation. The effect of probiotics on lymphocyte transformation is controversial, as Lee et al. (2011) demonstrated the effect of Lactobacilli treatment on splenic lymphocytes for $72 \mathrm{~h}$, and assessed cell viability by using the MTT assay. The effects of the strains on lymphocyte viability varied; some Lactobacilli had no effect, while others promoted lymphocyte transformation. Although, it is generally accepted that probiotics mediate differential activation of T cell subpopulations via modifying dendritic cells phenotype and function (Hart et al., 2004). The immuno-stimulatory effect of probiotic strains was assessed through metabolic activation of lymphocytes that may be influenced by cytokines that regulate apoptosis (Budd, 2002).

As it was shown in the present study, probiotics significantly $(P<0.05)$ declined the percentage of DNA in the comet tail indicating that probiotics may protect lymphocytes DNA from damage. These results coincide with the increase in ram lymphocyte transformation observed in the current work where comet assay has been often used in representing apoptosis of cells. Generally, in PMN cells probiotic can reduce the DNA damage caused by any endogenous or external source of stress. Such types of probiotics might be useful to protect animal cells in vivo from chemicals and heavy metal toxicity that cause DNA damage and genotoxicity. Numerous investigations indicated that probiotic bacteria can play an important role in natural processes of detoxification and elimination of heavy metals the body (Rao, 2009). To the best of our knowledge, the present study is the first to present the effect of probiotic strains mixture on lymphocytes and interleukins production in rams. Further investigation should be addressed to this topic taking into consideration the sample size, number of experimental rams and effect of each individual probiotic within the tested mixture on immune performance by measuring more cytokines concentrations to allow comprehensive understanding of the mechanism.

\section{Conclusions}

The present study demonstrated that lymphocytes transformation, leukocytes and cytokines production was differentially influenced by probiotic strains mixture. Moreover, probiotics may exert antiinflammatory effects via modulating interleukins IL-10/IL-12 ratio. The biological importance of these strain-specific effects remains to be determined.

\section{References}

Babar V., Thomas R., Bhaskar M., 2012. Immunomodulatory activity of Lactobacillus sporogenes. Int. J. Ther. Appl. 3, 32-38

Bien E., Balcerska A., Adamkiewicz-Drozynska E., Rapala M., Krawczyk M., Stepinski J., 2009. Pre-treatment serum levels of interleukin-10, interleukin-12 and their ratio predict response to therapy and probability of event-free and overall survival in childhood soft tissue sarcomas, Hodgkin's lymphomas and acute lymphoblastic leukemias. Clin. Biochem. 42, 1144-1157

Budd R.C., 2002. Death receptors couple to both cell proliferation and apoptosis. J. Clin. Invest. 109, 437-442

D'Andrea A., Aste-Amezaga M., Valiante N.M., Ma X., Kubin M., Trinchieri G., 1993. Interleukin 10 (IL-10) inhibits human lymphocyte interferon y-production by suppressing natural killer cell stimulatory factor/ IL- 12 synthesis in accessory cells. J. Exp. Med. 178, 1041-1048

de Moreno de LeBlanc A., Castillo N.A., Perdigón G., 2010. Anti-infective mechanisms induced by a probiotic Lactobacillus strain against Salmonella enterica serovar Typhimurium infection. Int. J. Food Microbiol. 138, 223-231

Dong H., Rowland I., Parveen Yaqoob P., 2012. Comparative effects of six probiotic strains on immune function in vitro. Brit. J. Nutr. 108, 459-470

Feldman B.F., Zinki J.G., Jain V.C., 2000. Laboratory techniques for avian hematology. In: Schalm's Veterinary Hematology. $5^{\text {th }}$ Edition. Lippincott Williams \& Wilkins. Toronto (Canada), pp. $1145-1146$

Galdeano C.M., Perdigón G., 2006. The probiotic bacterium Lactobacillus casei induces activation of the gut mucosal immune system through innate immunity. Clin. Vaccine Immunol. 13, 219-226

Gao S., Wang Y., Zhang P., Dong Y., Li B., 2008. Subacute oral exposure to dibromoacetic acid induced immunotoxicity and apoptosis in the spleen and thymus of the mice. Toxicol. Sci. $105,331-341$

Guillen L.M., 2009. Determination of the mechanism(s) by which directfed microbials control Escherichia coli 0157:H7 in cattle. PhD. Thesis, Oklahoma State University (USA) http://digital.library. okstate.edu/etd/Guillen_okstate_0664D_10201.pdf

Hamer H.M., Jonkers D.M., Vanhoutvin S.A., Troost F.J., Rijkers G., de Bruïne A., Bast A., Venema K., Brummer R.J., 2010. Effect of butyrate enemas on inflammation and antioxidant status in the colonic mucosa of patients with ulcerative colitis in remission. Clin. Nutr. 29, 738-744

Hart A.L., Lammers K., Bigidi P., Vitali B., Rizzello F., Gionchetti P., Campieri M., Kamm M.A., Knight S.C., Stagg A.J., 2004. Modulation of human dendritic cell phenotype and function by probiotic bacteria. Gut 53, 1602-1609

Hessle C., Andersson B., Wold A.E., 2000. Gram-positive bacteria are potent inducers of monocytic interleukin-12 (IL-12) while gram-negative bacteria preferentially stimulate $\mathrm{IL}-10$ production. Infect. Immunol. 68, 3581-3586

Hua M.C., Lin T.Y., Lai M.W., Kong M.S., Chang H.J., Chen C.C., 2010. Probiotic Bio-three induces Th1 and antiinflammatory effects in PBMC and dendritic cells. World J. Gastroenterol. 16, 3529-3540

Ishikawa F., Miyazaki S., 2005. A functional role of neutrophils in the regulation of innate and acquired immunity to bacterial infection. Pak. J. Biol. Sci. 8, 940-948

Ismail S.H., 2013. Effects of probiotics supplementation on some blood indices in Iraq diabetic patients. Pharmacie Globale (IJCP) 4 (8), 1-4 
Kizilian N., Wilkins R.C., Reinhardt P., Ferrarotto C., McLean J.R.N., McNamee J.P., 1999. Silver-stained comet assay for detection of apoptosis. Biotechniques 27, 926-928

Kuitunen M., 2013. Probiotics and prebiotics in preventing food allergy and eczema. Curr. Opin. Allergy Clin. Immunol. 13, 280-286

Kunavue N., Lien T.F., 2012. Effects of fulvic acid and probiotic on growth performance, nutrient digestibility, blood parameters and immunity of pigs. J. Anim. Sci. Adv. 2, 711-721

Lebeer S., Vanderleyden J., De Keersmaecker S.C., 2008. Genes and molecules of lactobacilli supporting probiotic action. Microbiol. Mol. Biol. Rev. 72, 728-764

Lee J., Yun H.S., Cho K.W., Oh S., Kim S.H., Chun T., Kim B., Whang K.Y., 2011. Evaluation of probiotic characteristics of newly isolated Lactobacillus spp.: Immune modulation and longevity. Int. J. Food Microbiol. 148, 80-86

Lopez P., Gueimonde M., Margolles A., Suárez A., 2010. Distinct Bifidobacterium strains drive different immune responses in vitro. Int. J. Food Microbiol. 138, 157-165

Medina M., Izquierdo E., Ennahar S., Sanz Y., 2007. Differential immunomodulatory properties of Bifidobacterium logum strains: relevance to probiotic selection and clinical applications. Clin. Exp. Immunol. 150, 531-538
Mileti E., Matteoli G., lliev I.D., Rescigno M., 2009. Comparison of the immunomodulatory properties of three probiotic strains of Lactobacilli using complex culture systems: prediction for in vivo efficacy. PLoS One 4 (9), e7056

Nicole C., Dan D., 2010. Probiotics identification and ways of action. Innov. Rom. Food Biotechnol. 6, 1-11

Osman M.A., 2012. Modification of the Animal Immune System by Feeding Probiotics. Graduate Theses and Dissertations. Paper, 12424. lowa State University, lowa (USA)

Rao K.S., 2009. Free radical induced oxidative damage to DNA: relation to brain aging and neurological disorders. Indian J. Biochem. Biophys. 46, 9-15

Vizoso Pinto M.G., Rodriguez Gomez M., Seifert S., Watzl B., Holzapfel W.H., Franz C.M., 2009. Lactobacilli stimulate the innate immune response and modulate the TLR expression of HT29 intestinal epithelial cells in vitro. Int. J. Food Microbiol. $133,86-93$ 